\title{
Epilepsiechirurgie in Semarang
}

In deze bijdrage een korte impressie van het epilepsiechirurgieprogramma in het Dr. Kariadi ziekenhuis in Semarang. Dit is het enige ziekenhuis in Indonesië waar patiënten met epilepsie worden geopereerd. Voor de ontwikkeling van expertise wordt gestreefd naar uitbreiding van samenwerking met landen waar veel ervaring is met (invasief) prechirurgisch onderzoek dat kan leiden tot aanvalsvrijheid na een resectie, zoals in Nederland.

In I925 werd in Centraal Java (Indonesië) het gebouw van de Centrale Burgerlijke Ziekeninrichting (CBZ) opgeleverd. In figuur $\mathrm{I}$ is een afbeelding te zien van de oorspronkelijke ingang van het CBZ. Bij de verovering van dit ziekenhuis op de Japanse bezetters (in I945) kwamen dr. Kariadi en acht medewerkers van het ziekenhuis om het leven. Daarom kreeg dit ziekenhuis later (in 1964) ter nagedachtenis aan dr. Kariadi, zijn naam, het Dr. Kariadi General Hospital Medical Center, dat is gelieerd aan de medische faculteit van de Diponegoro University. over de middelen. Dit bepaalt welke onderzoeken gedaan kunnen worden gedurende het pre-chirurgische evaluatietraject. In het Dr. Kariadi ziekenhuis wordt MRI-onderzoek verricht. Hiervoor zijn twee I.5 Tesla scanners beschikbaar en er wordt langdurig EEG-onderzoek gedaan. Het preoperatieve video-EEG-onderzoek komt overeen met de werkwijze in Nederland, dat wil zeggen monitoring gedurende vijf tot zeven dagen, waarbij de patiënt zich overdag vrij kan bewegen in een huiskamer. Het ziet er allemaal wat minder 'gelikt' uit dan in Nederland, maar het ís er
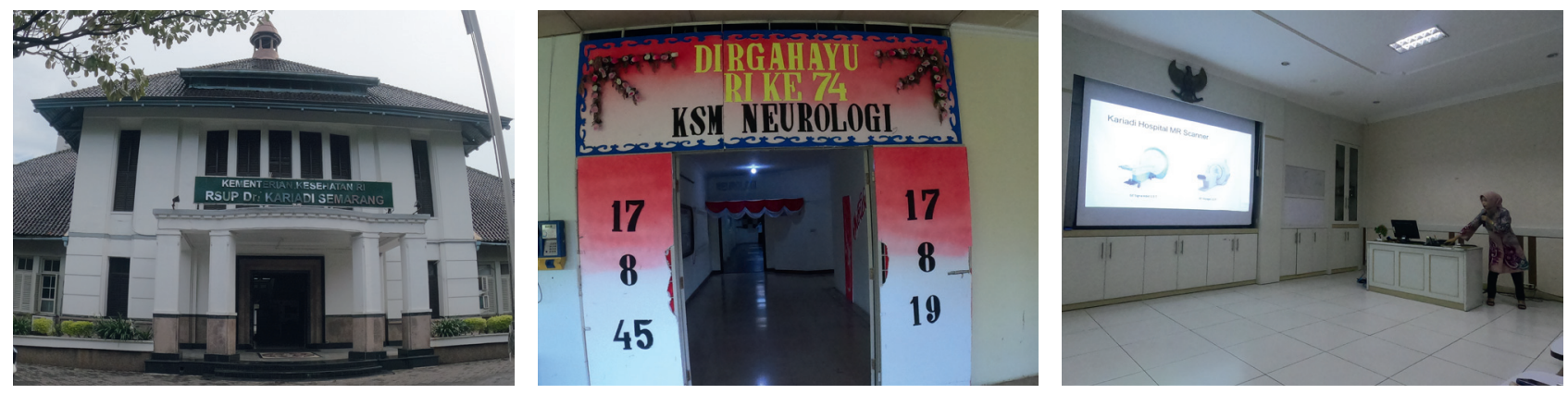

Figuur 1 Links de ingang van de Centrale Burgerlijke Ziekeninrichting (CBZ), zoals dat in 1925 werd opgeleverd, midden de ingang van de afdeling neurologie van het Dr. Kariadi ziekenhuis en rechts een spreekster tijdens een van de workshops waar de auteurs een bijdrage aan mochten leveren.

\section{Epilepsiechirurgie in Semarang}

Het Dr. Kariadi ziekenhuis is het enige ziekenhuis in Indonesië waar epilepsiechirurgie wordt gedaan. Het epilepsiechirurgieprogramma werd ontwikkeld in samenwerking met Hiroshima University (Japan) en functioneert sinds 2004 zelfstandig. Er worden per jaar 50 tot 60 operaties uitgevoerd bij patiënten met een focale epilepsie, een laag percentage op een bevolking van 264 miljoen inwoners. Patiënten die in aanmerking komen voor operatie kunnen patiënten zijn met een temporaalkwabepilepsie, maar ook met een frontale, pariëtale of enige andere vorm van focale epilepsie. Ook hier geldt, zoals in andere landen die in ontwikkeling zijn, dat de kennis aanwezig is; het probleem is het kunnen beschikken allemaal wel, althans de apparatuur voor de initiële diagnose van een epilepsiechirurgiekandidaat. Voor een PET-onderzoek wordt de patiënt naar Jakarta verwezen, waar twee PET-scanners staan. Indien dit alles tot een operatie leidt, kan in het Dr. Kariadi ziekenhuis intraoperatieve elektro-corticografie worden gedaan.

\section{Samenwerking}

Er is een langer bestaande formele samenwerking tussen het onderwijsinstituut Psychologie van de Radboud Universiteit Nijmegen en de universiteit Diponegoro/Kariadi. In een volgend nummer van 'Epilepsie' zal hier uitgebreider aandacht voor zijn. 
2 - 4 april 2020

$4^{\text {th }}$ International Video-EEG in Paediatric Epilepsies from Seizures to Syndromes

Locatie: Madrid, Spanje

Informatie: www.ilae.org/congresses/4th-international-videoeeg-in-paediatric-epilepsies-from-seizures-to-syndromes

\section{8 - 9 mei 2020}

International Epilepsy 2020: A vision of the future in epilepsy research

Locatie: Montreal, Canada

Informatie: www.mcgill.ca/neuro/channels/event/epilepsy2020-vision-future-epilepsy-research-300406

\section{I4 - 17 mei 2020}

International Training Course on Neuroimaging of Epilepsy

Locatie: Montreal, Canada

Informatie: www.ilae.org/congresses/3rd-internationaltraining-course-on-neuroimaging-of-epilepsy

23 - 26 mei 2020

II $^{\text {th }}$ Latin American Congress on Epilepsy 2020 (LACE)

Locatie: Medellín, Colombia

Informatie: www.epilepsycongress.org/lace

\section{3- 5 juni 2020}

$2^{\text {nd }}$ International Course on PET and SEEG in Epilepsy Surgery

Locatie: Londen, Verenigd Koninkrijk

Informatie: www.ilae.org/congresses/2nd-internationalcourse-on-pet-and-seeg-in-epilepsy-surgery

\section{7 - Io juni 2020}

$15^{\text {th }}$ Eilat Conference on New Antiepileptic Drugs \& Devices (EILAT XV)

Locatie: Madrid, Spanje

Informatie: www.eilatxv.com

\section{I0 - 13 juni 2020}

55. Jahrestagung der Deutschen Gesellschaft für Epileptologie (DGfE)

Locatie: Freiburg im Breisgau, Duitsland

Informatie: www.ilae.org/congresses/55-jahrestagung-derdeutschen-gesellschaft-f-r-epileptologie-dgfe
IO - I3 juni 2020

$3^{\circ}$ Congresso da Liga Brasileira de Epilepsia -

Curitiba 2020

Locatie: Curitiba, Brazilië

Informatie: www.ilae.org/congresses/38-congresso-da-

liga-brasileira-de-epilepsia-curitiba-2020

I8 - 21 juni 2020

${ }_{10}{ }^{\text {th }}$ Migrating Course on Epilepsy

Locatie: Lviv, Oekraïne

Informatie: www.ilae.org/congresses/Ioth-migrating-

course-on-epilepsy

19 - 2 I juni 2020

$2 \mathrm{I}^{\text {st }}$ Annual Meeting of Infantile Seizure Society International Symposium (ISSET)

Locatie: Okayama, Japan

Informatie: www.ilae.org/congresses/2 Ist-annual-meetingof-infantile-seizure-society-international-symposium-isset

4 - 9 juli 2020

$14^{\text {th }}$ European Congress on Epileptology (ECE)

Locatie: Genève, Zwitserland

Informatie: www.ilae.org/congresses/I4th-european-

congress-on-epileptology-ece

9 - 10 juli 2020

ESTM Epilepsy Surgery Techniques Meeting

Locatie: Genève, Zwitserland

Informatie: www.estm2020.com

20 - 3I juli 2020

2020 Advanced San Servolo Epilepsy Course

Locatie: San Servolo, Venetië, Italië

Informatie: www.ilae.org/congresses/2020-advanced-san-

servolo-epilepsy-course

9 - I5 augustus 2020

$14^{\text {th }}$ Baltic Sea Summer School on Epilepsy

Locatie: Sigulda, Letland

Informatie: www.epilepsiestiftung-wolf.de

25 - 27 september 2020

First North American Epilepsy Congress

Locatie: Toronto, Canada

Informatie: www.ilae.org/congresses/rst-north-americanepilepsy-congress-naec

De productie van dit blad is mogelijk gemaakt door financiële ondersteuning van:

Epilepsiefonds

ஸ่D

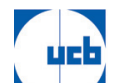
Inspired by patients. Driven by science.
UCB Pharma B.V.

Liva Nova Nederland N.V.
Eisai B.V.

\section{Liva Nova}

